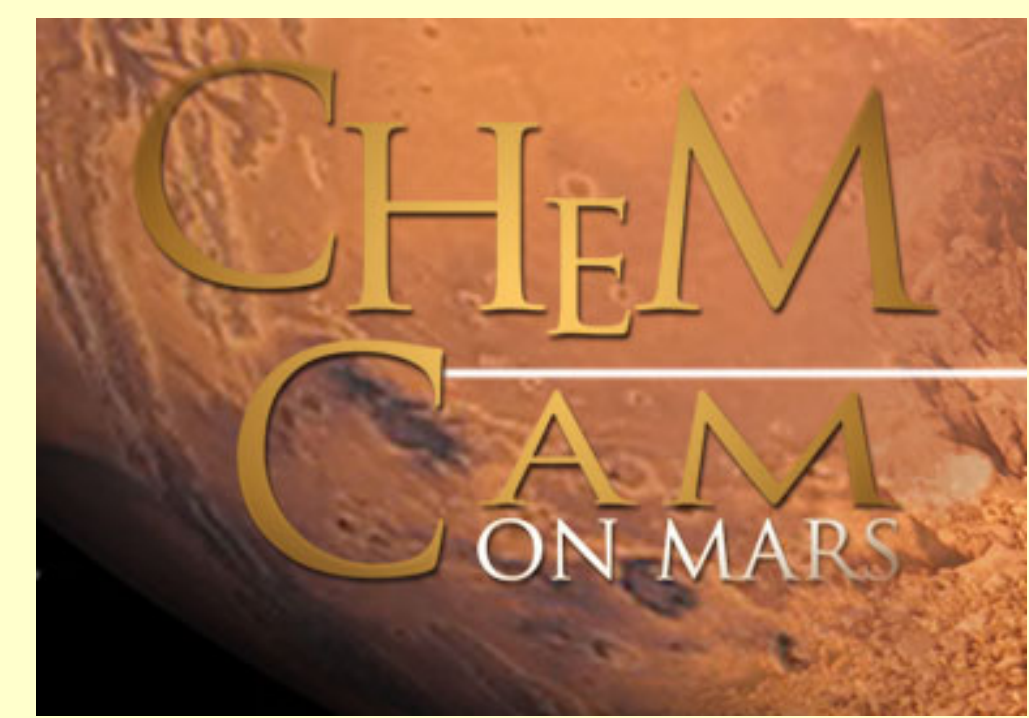

\title{
Long distance observations with the ChemCam Remote Micro-Imager: Mount Sharp and related deposits on Gale Crater floor
}

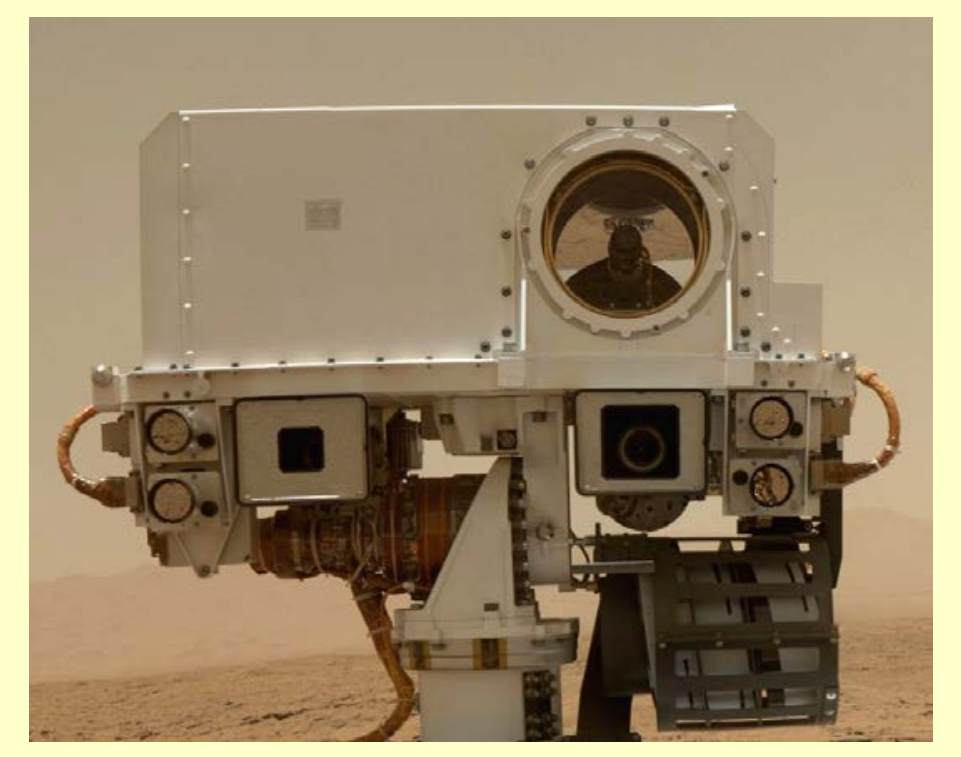

Horton Newsom ${ }^{1}$, Olivier Gasnault ${ }^{2}$, Stéphane Le Mouélic ${ }^{3}$, Nicolas Mangold ${ }^{3}$, Laetitia Le Deit ${ }^{3}$, Roger Wiens ${ }^{4}$, Ryan Anderson ${ }^{5}$, Lauren Edgar ${ }^{5}$, Ken Herkenhoff ${ }^{5}$, Jeffrey R. Johnson ${ }^{6}$, Nathan Bridges ${ }^{6}$, John P. Grotzinger ${ }^{7}$, Sanjeev Gupta ${ }^{8}$, Samantha Jacob ${ }^{9}$

1. Univ. of New Mexico, Albuquerque, NM, United States, 2. IRAP, Toulouse, France, 3. LPG-Nantes, Nantes, France, 4. Los Alamos National Lab, Los Alamos, NM, United States, 5. USGS Flagstaff, Flagstaff, AZ, United States, 6. Johns Hopkins APL, Laurel, MD, United States, 7. Caltech, Pasadena, CA, United States, 8. Imperial College, London, United Kingdom, 9. Univ. of Hawaii, Honolulu, HI, United States

Geological Society of America, Sept. 26, 2016 


\section{RMI pixel scale: better than HiRISE up to $\sim 12 \mathrm{~km}$}

The RMI imager has the finest pixel scale on the rover $(19.6 \mu \mathrm{rad} /$ pixel), with $\sim 2 \mathrm{~cm}$ resolution at $1 \mathrm{~km}$, and $\sim 26 \mathrm{~cm}$ at $12 \mathrm{~km}$, beyond which the most powerful orbital camera (HiRISE) resolution is better.

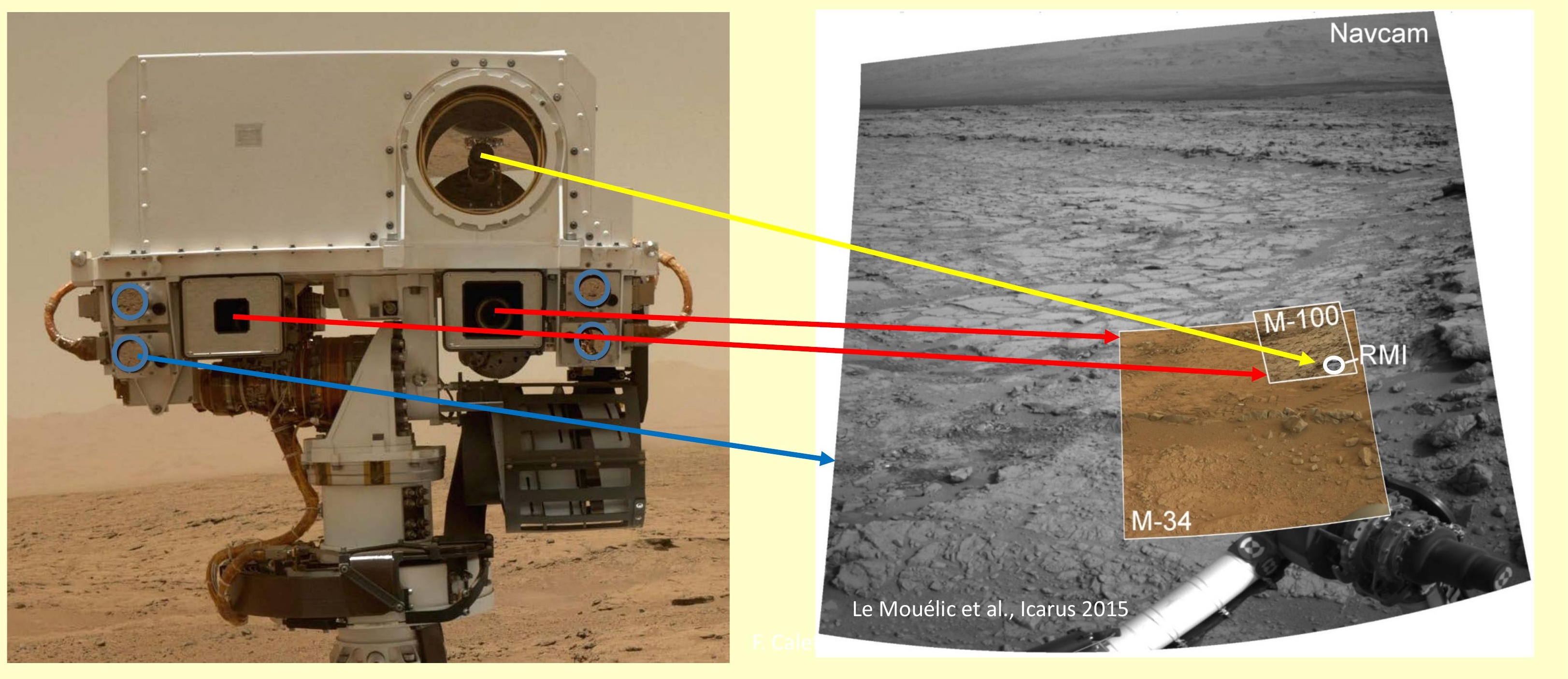




\section{Long Distance RMI Campaigns}

- Peace Vallis Fan

- Goals:

- Determine the nature of alluvial fan deposition from face-on images of the eroded fan

- Investigate the origin of the inverted channel deposits from layering and features on their sides

- Aeolis Planum and Gale Rim

- Goal:

- Observe remnants of early Gale Crater sedimentary deposits in contact with the rim, that may have preceded the Peace Vallis Fan to understand the early deposition and erosion of the crater

- Light-toned Yardang-forming Unit

- Goal:

- Observe fine-scale bedding geometry compared to the sloping yardang orientation to test the origin of the deposits, including a deltaic clinoform hypothesis, aeolian or other depositional models

- Steep slope activity and processes

- Goals:

- Observe and monitor highly-visible slopes identified in HiRISE for any activity or changes 


\section{Peace Vallis \\ Fan}

- Dashed lines are inverted channels

- Studied from orbital data by Palucis et al., 2015

- New observations from the MSL rover perspective, 2016

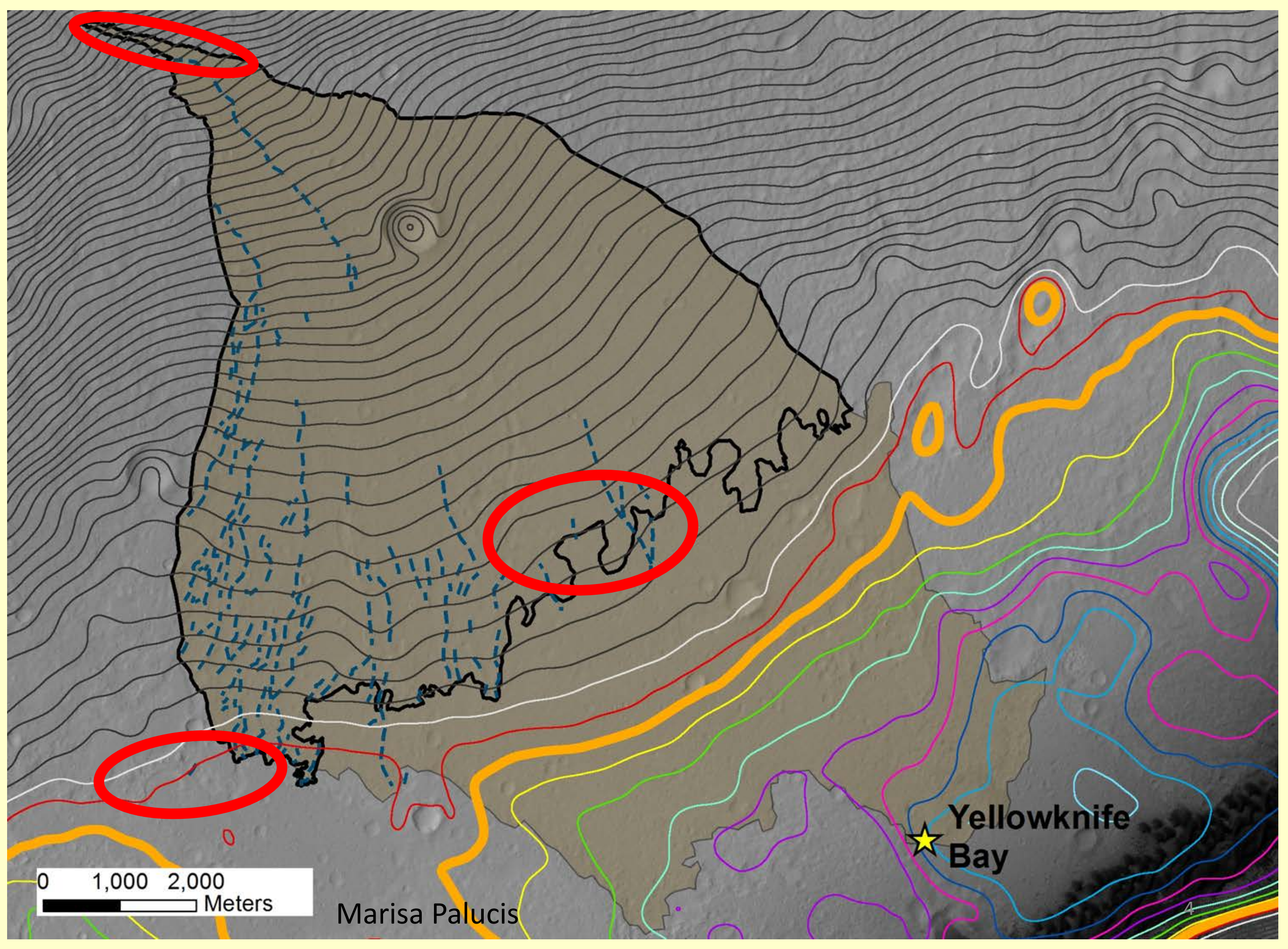




\section{How deeply was Gale crater filled with sediment?}

- Currently the sediments of Mt. Sharp only partially fill the crater, but these sediments are clearly eroded and extended further into the basin

- There is a > $200 \mathrm{MY}$ time period after formation of the crater ( $3.6 \mathrm{BY}$ ) and before the present crater form was reached at $\sim 3.2 \mathrm{BY}$ when burial and erosion could have occurred

- Remnants of early deposits would be expected on the crater rim

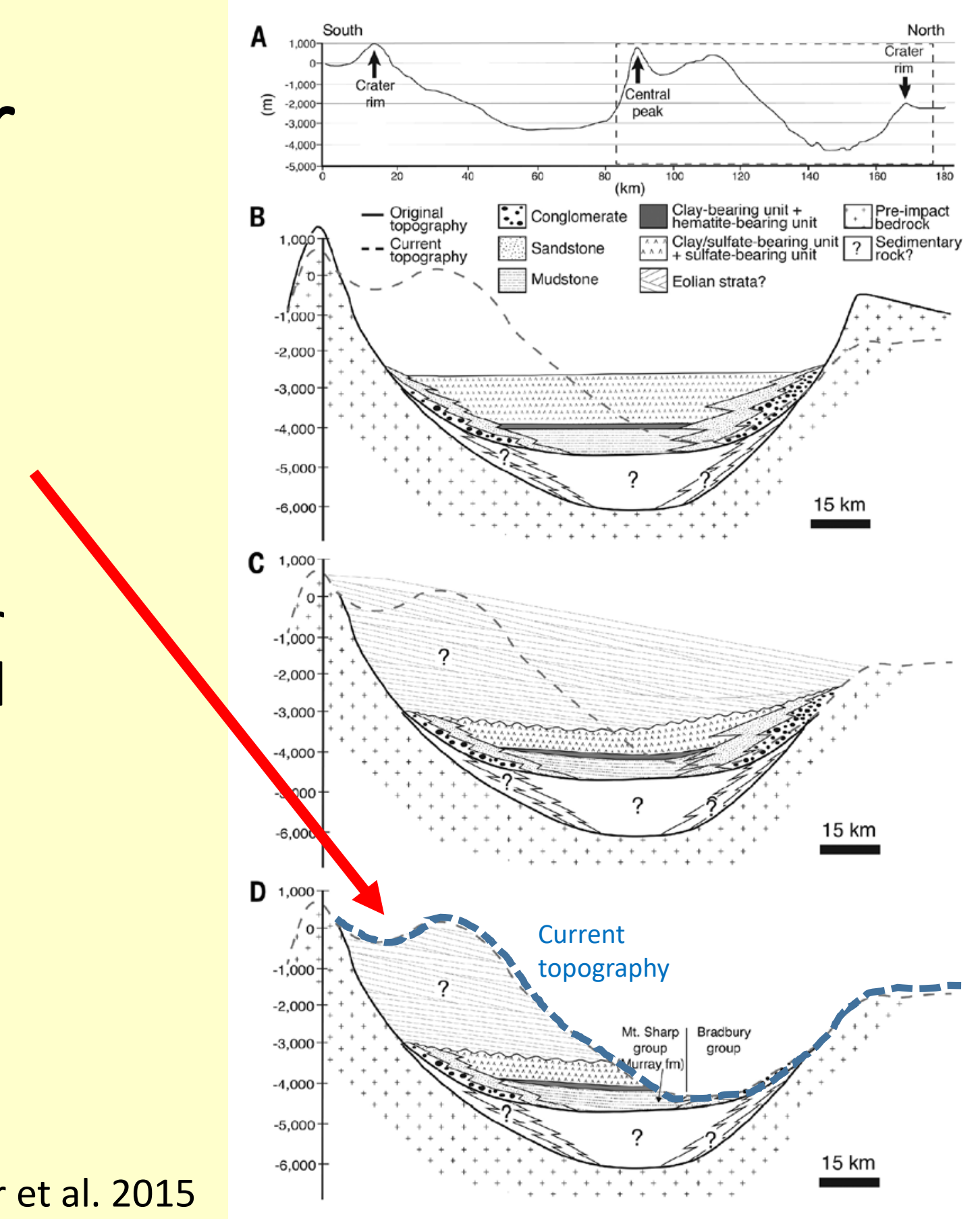




\section{How deeply was Gale crater filled with sediment?}

- Currently the sediments of Mt. Sharp only partially fill the crater, but these sediments are clearly eroded and extended further into the basin

- There is a > $200 \mathrm{MY}$ time period after formation of the crater ( $3.6 \mathrm{BY}$ ) and before the present crater form was reached at $\sim 3.2 \mathrm{BY}$ when burial and erosion could have occurred

- Remnants of early deposits would be expected on the crater rim
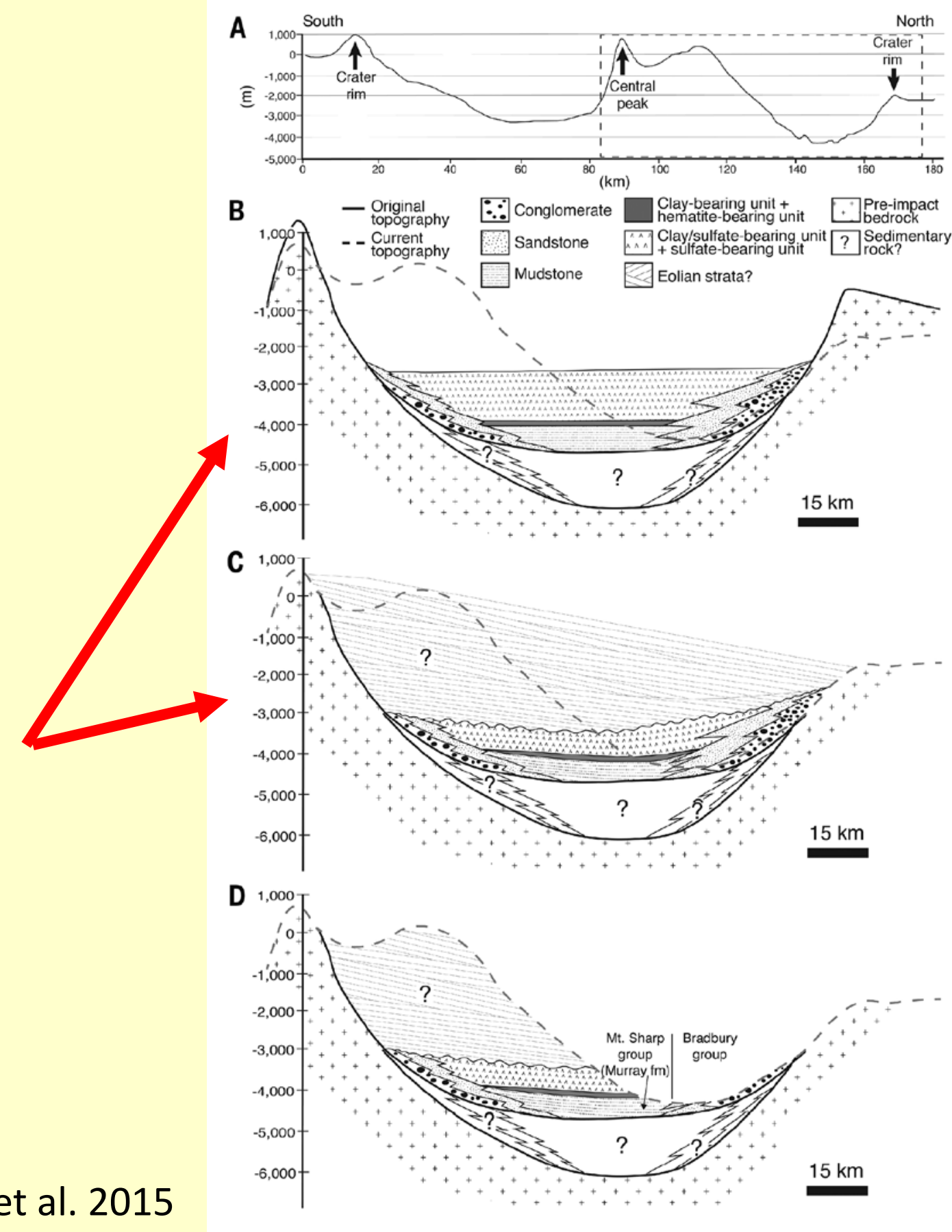


\section{How deeply was Gale crater filled with sediment?}

- Currently the sediments of Mt. Sharp only partially fill the crater, but these sediments are clearly eroded and extended further into the basin

- There is a > $200 \mathrm{MY}$ time period after formation of the crater ( $3.6 \mathrm{BY}$ ) and before the present crater form was reached at $\sim 3.2 \mathrm{BY}$ when burial and erosion could have occurred

- Remnants of early deposits would be expected on the crater rim
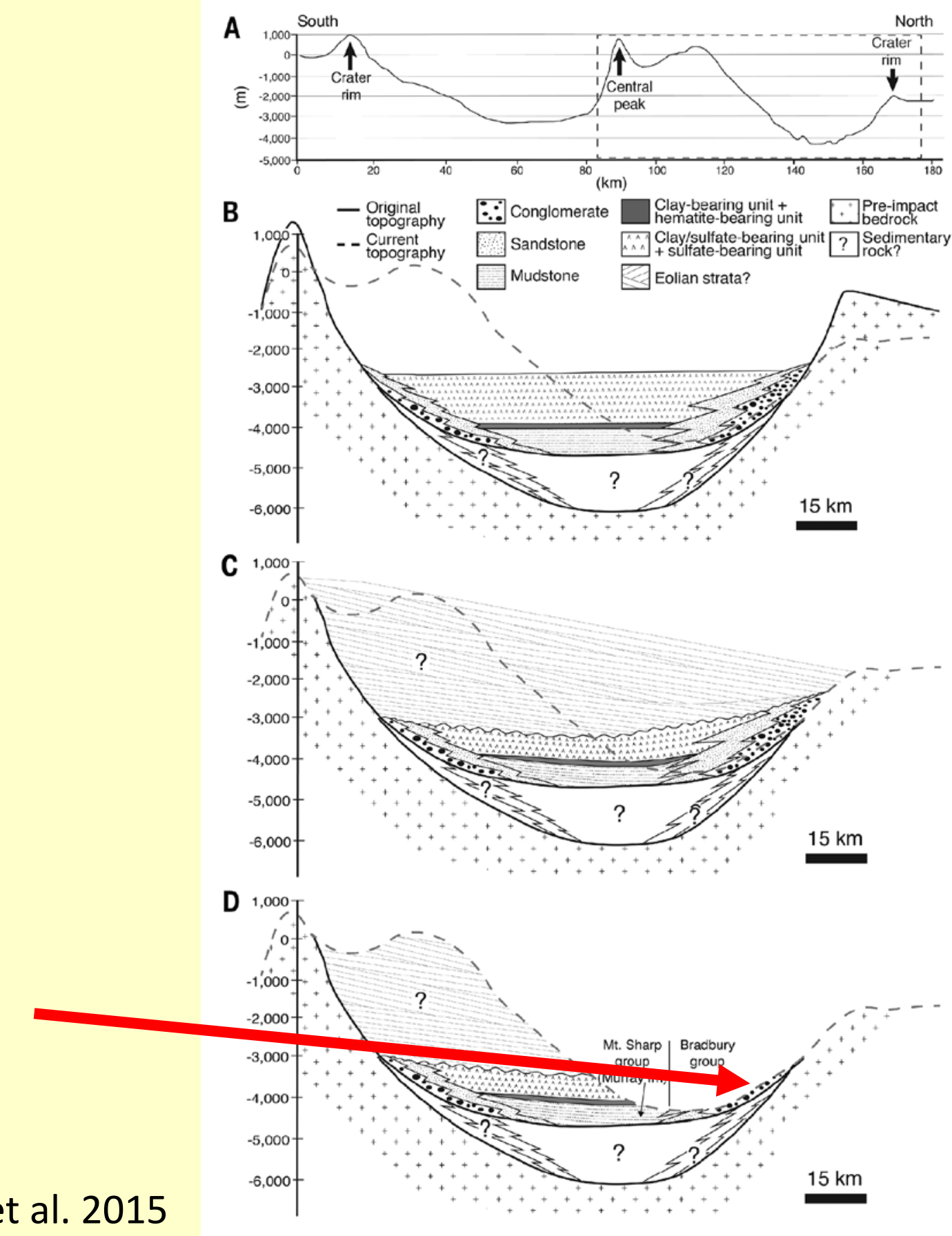
Mastcam image of the Peace Vallis Fan head channel ( $25 \mathrm{~km}$ range)

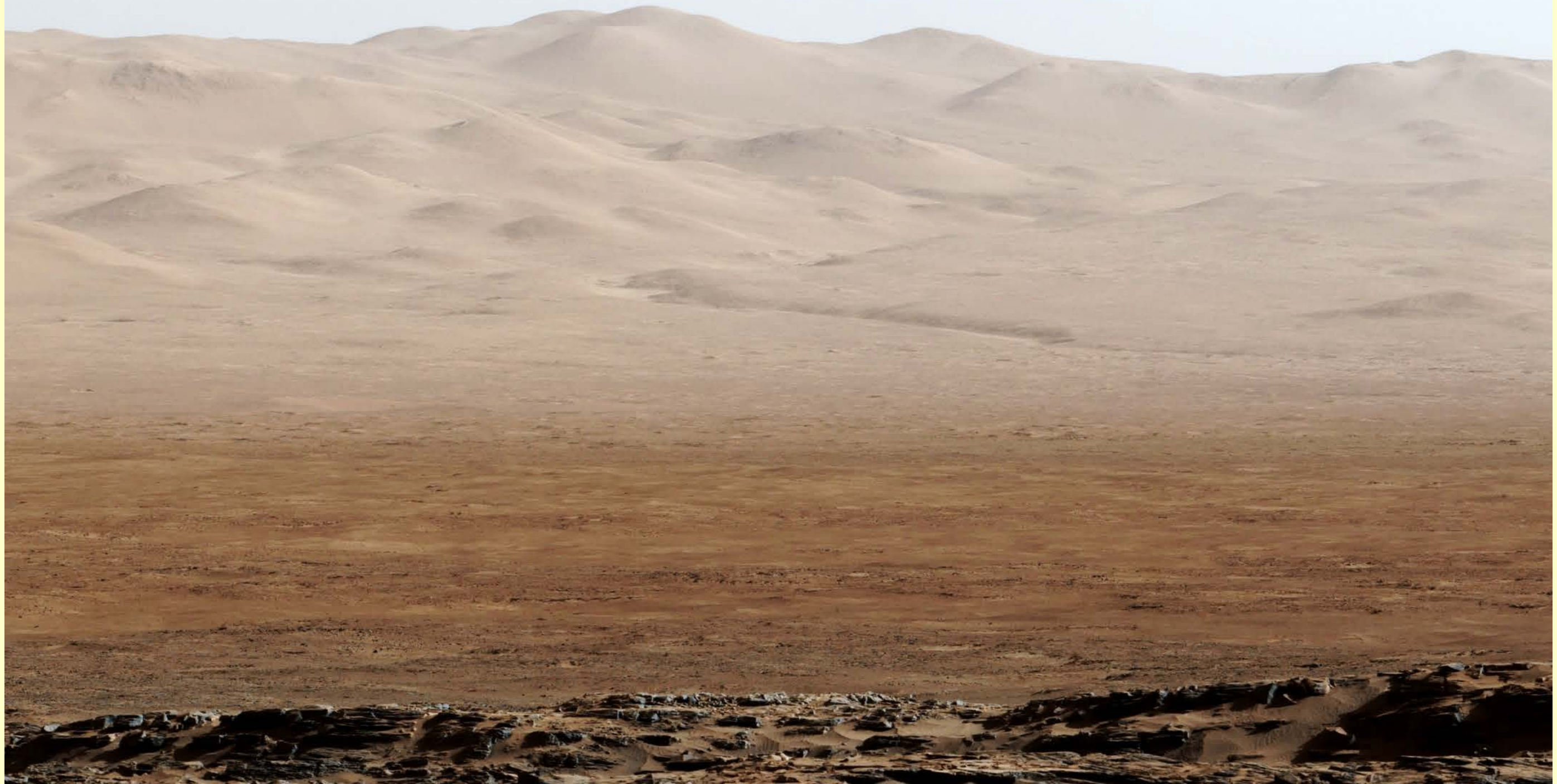


Peace Vallis Fan head channel with two superimposed 10 image RMI mosaics ( $25 \mathrm{~km}$ range) 
Peace Vallis channel bend - note horizontal beds probably incised by channel in background (arrows)

Peace Vallis campaign - RMI - sol 1300

Portion of ChemCam RMI mosaic 


\section{Remnant layered deposits embayed by Fan deposits}

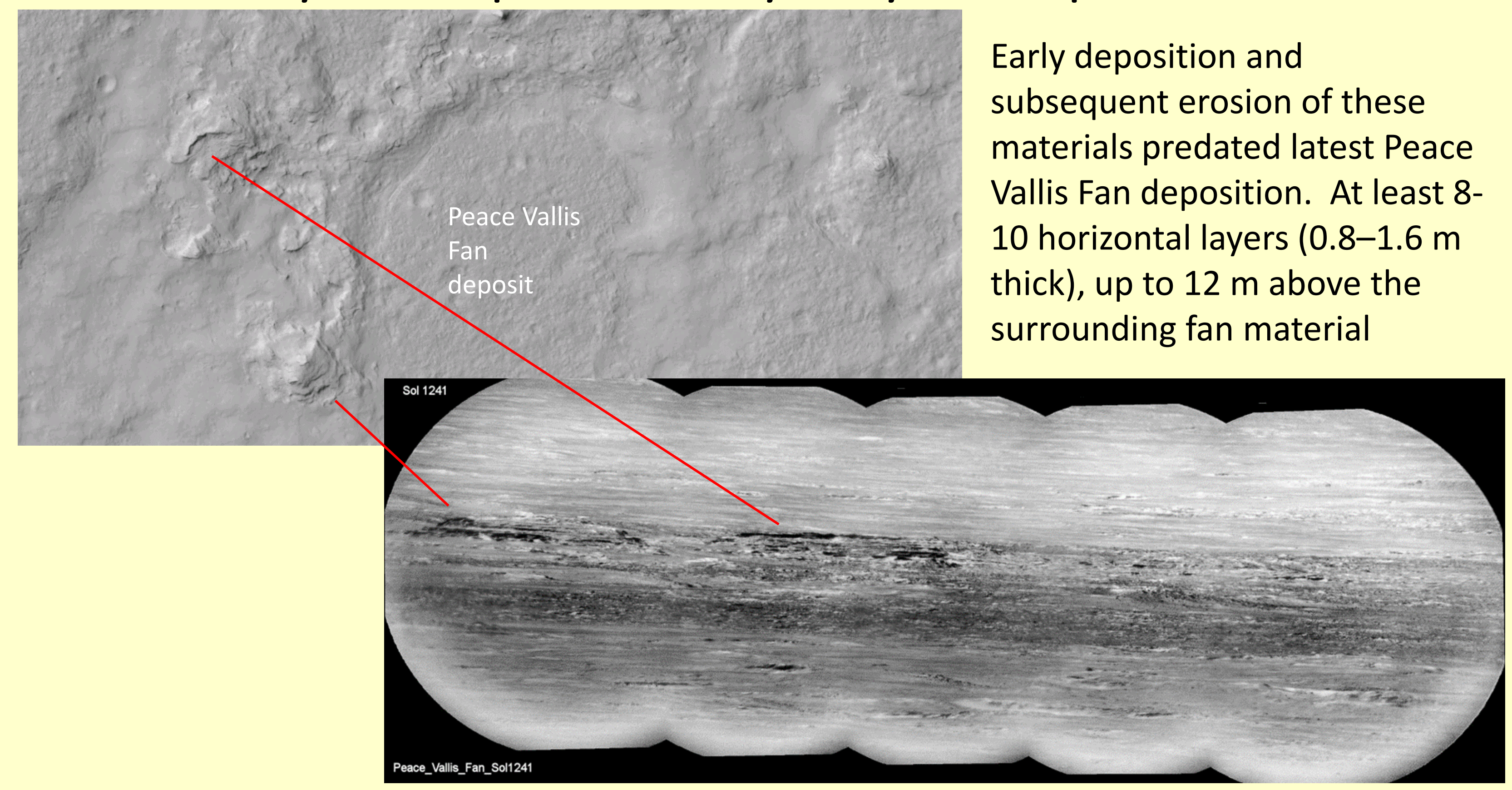


Context - Peace Vallis Fan - eroded face, fan structure

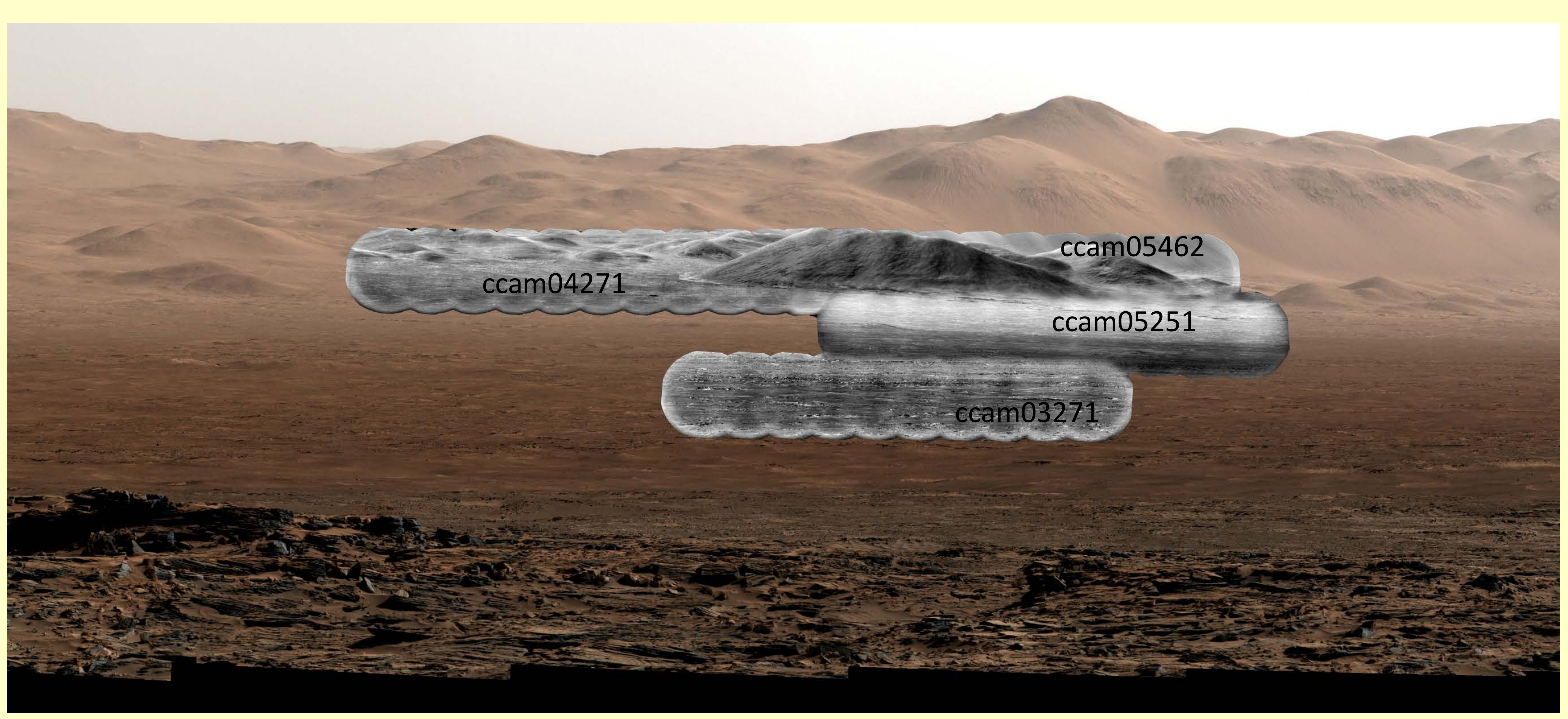




\section{Peace Vallis Fan oblique view showing the depositional layers}

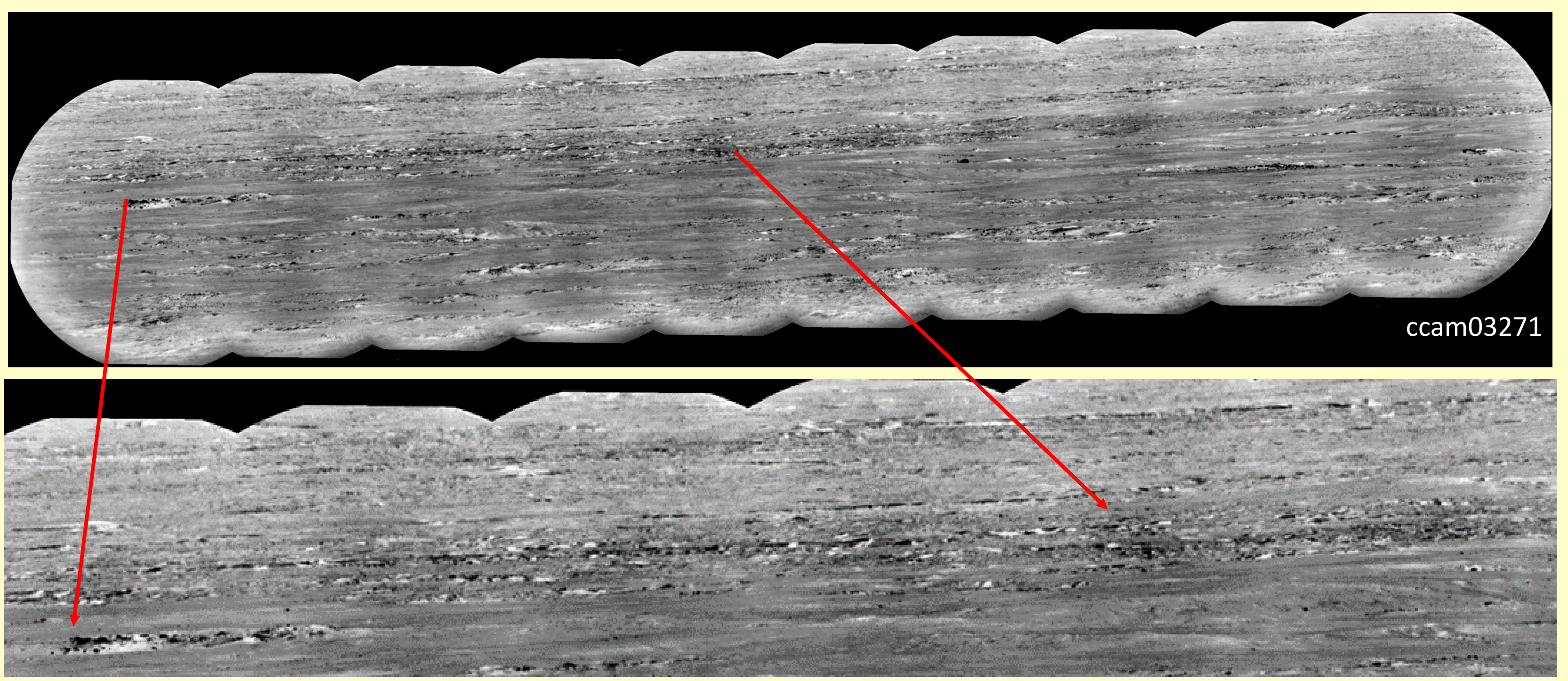

Thin extensive layers - sheet flood deposits? Comparison with terrestrial fans? 


\section{Terrestrial fan analogue? - Death Valley}

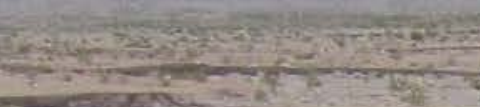

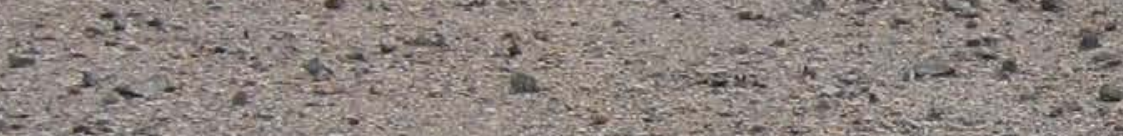

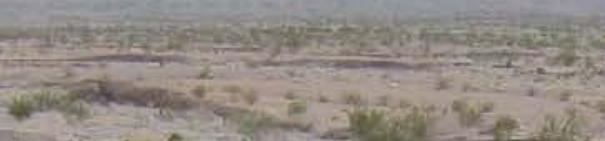




\section{Mt. Sharp Light Toned Yardang-Forming Unit}

- This unit is uncratered and lies unconformably on underlying strata

- "Fluted" texture is interpreted as yardangs, but the relationship with bedding is not clear in orbital images

- Initial Mastcam images from the rover showed apparent sloping features reminiscent of deltaic clinoforms

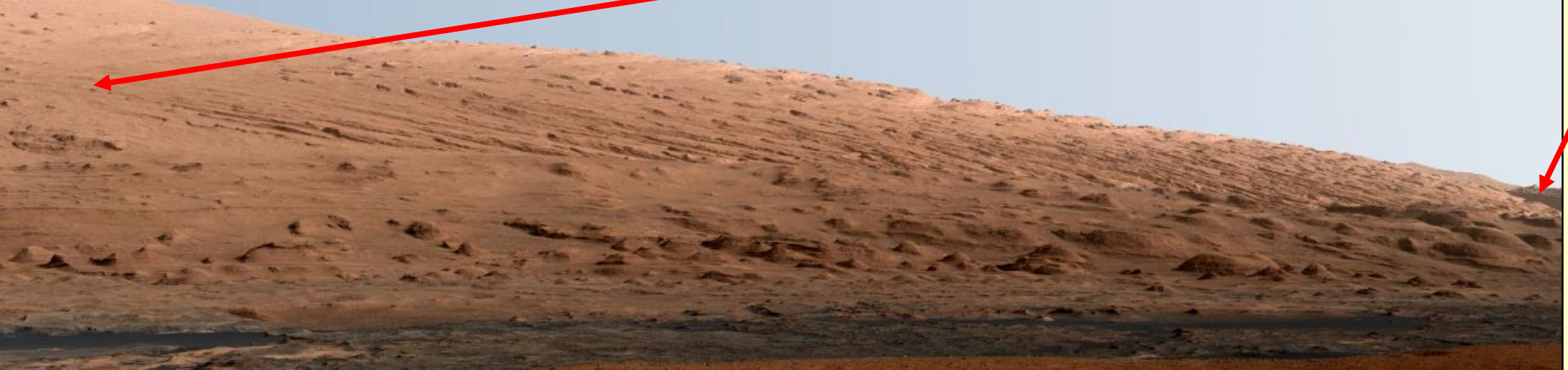




\section{RMI images resolve bedding in the yardang unit}

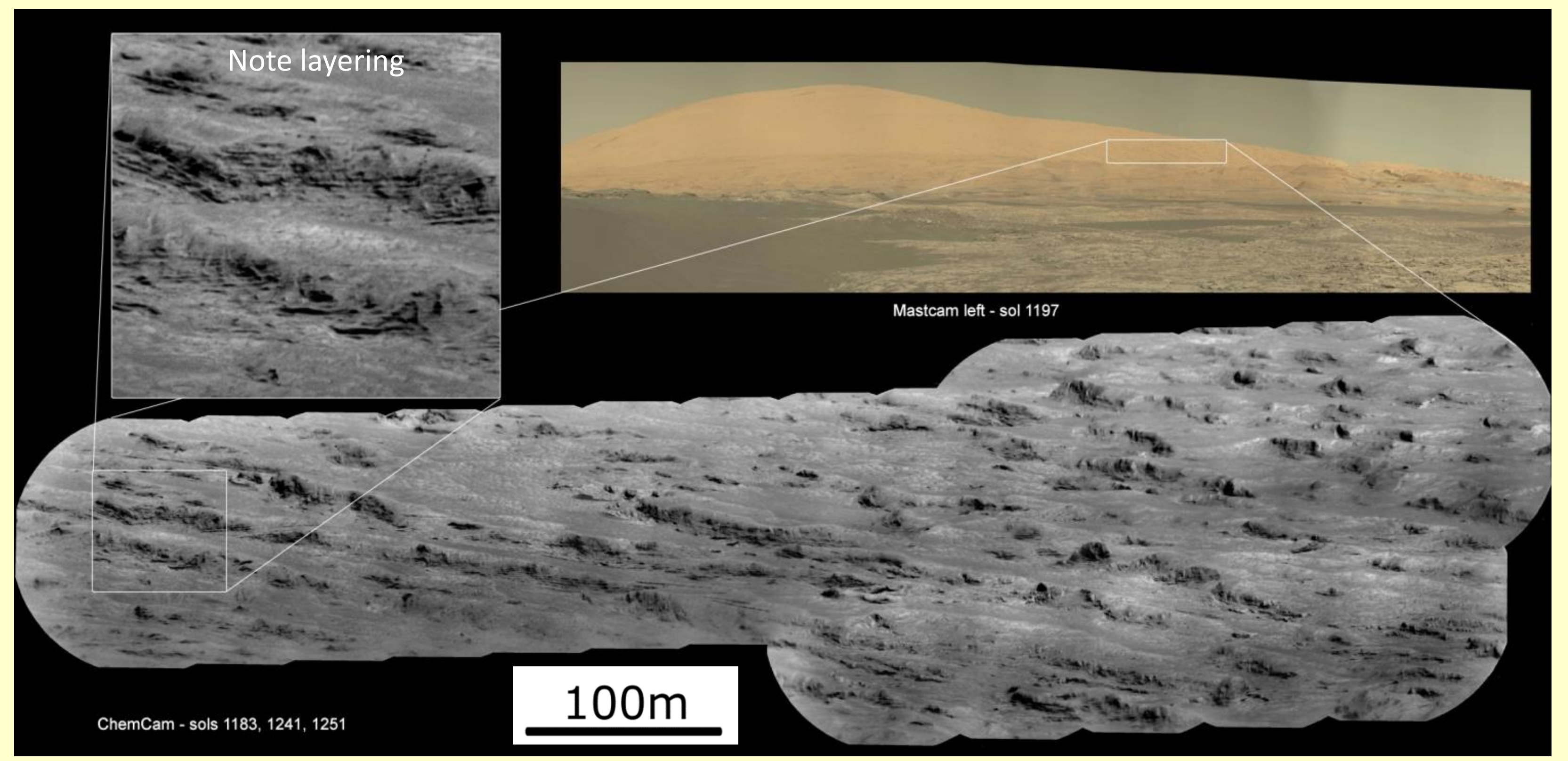

Distance $\sim 9.2 \mathrm{~km}, \mathrm{RMI}$ FOV $\sim 20 \mathrm{mrad} \sim 180 \mathrm{~m}$ 


\section{RMI observations and}

interpretation The visible bedding seen in RMI images forms subhorizontal bedding sets with variable dip directions that cut across the yardangs, and are sometimes aligned with the yardangs. No obvious cross-bed sets are visible. No evidence of major slope failure is visible The surface is young and rapidly eroding

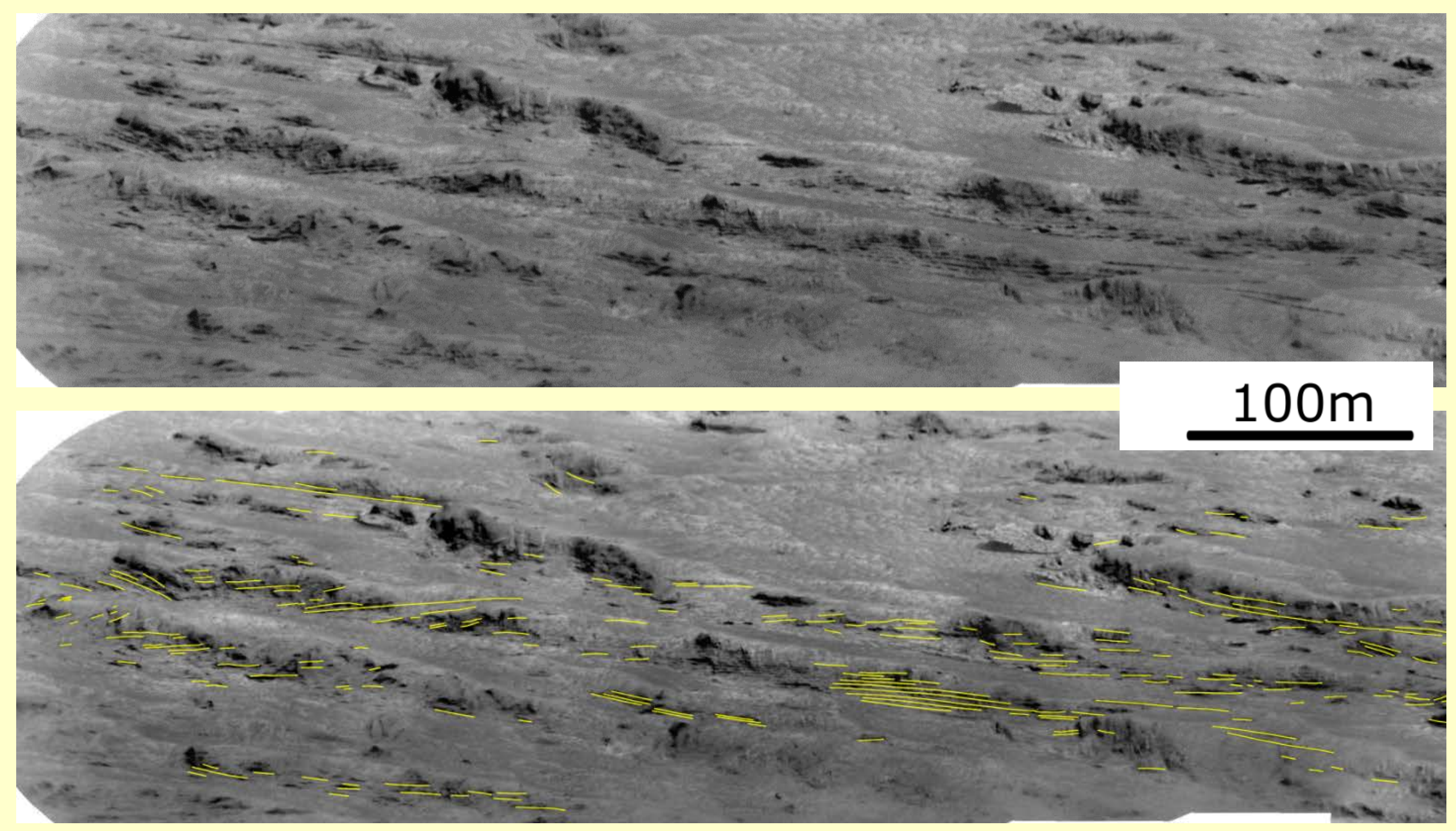

The observations are most consistent with an aeolian air fall deposit, possibly volcanic ash. The deposit may be related to the Medusae Fossae deposits north of Gale Crater. 


\section{Monitoring Slope Activity}

- Dundas \& McEwen (2015) identified multiple locations on Mt. Sharp that exhibit streaks or lineae

- With long-distance RMI we can view these features better than HiRISE

- Repeat observations can help determine if the features are active and the nature of erosion on steep slopes

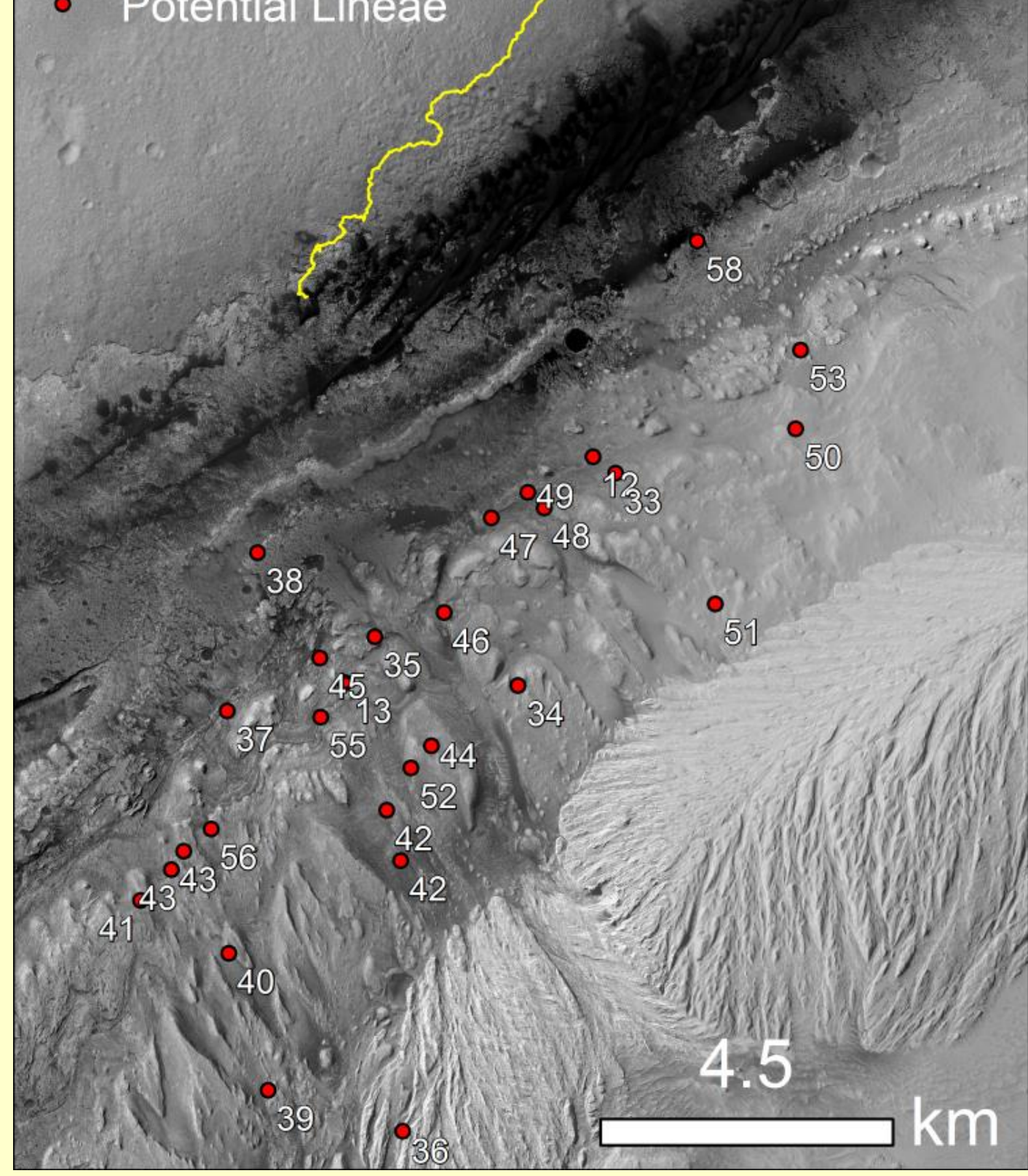




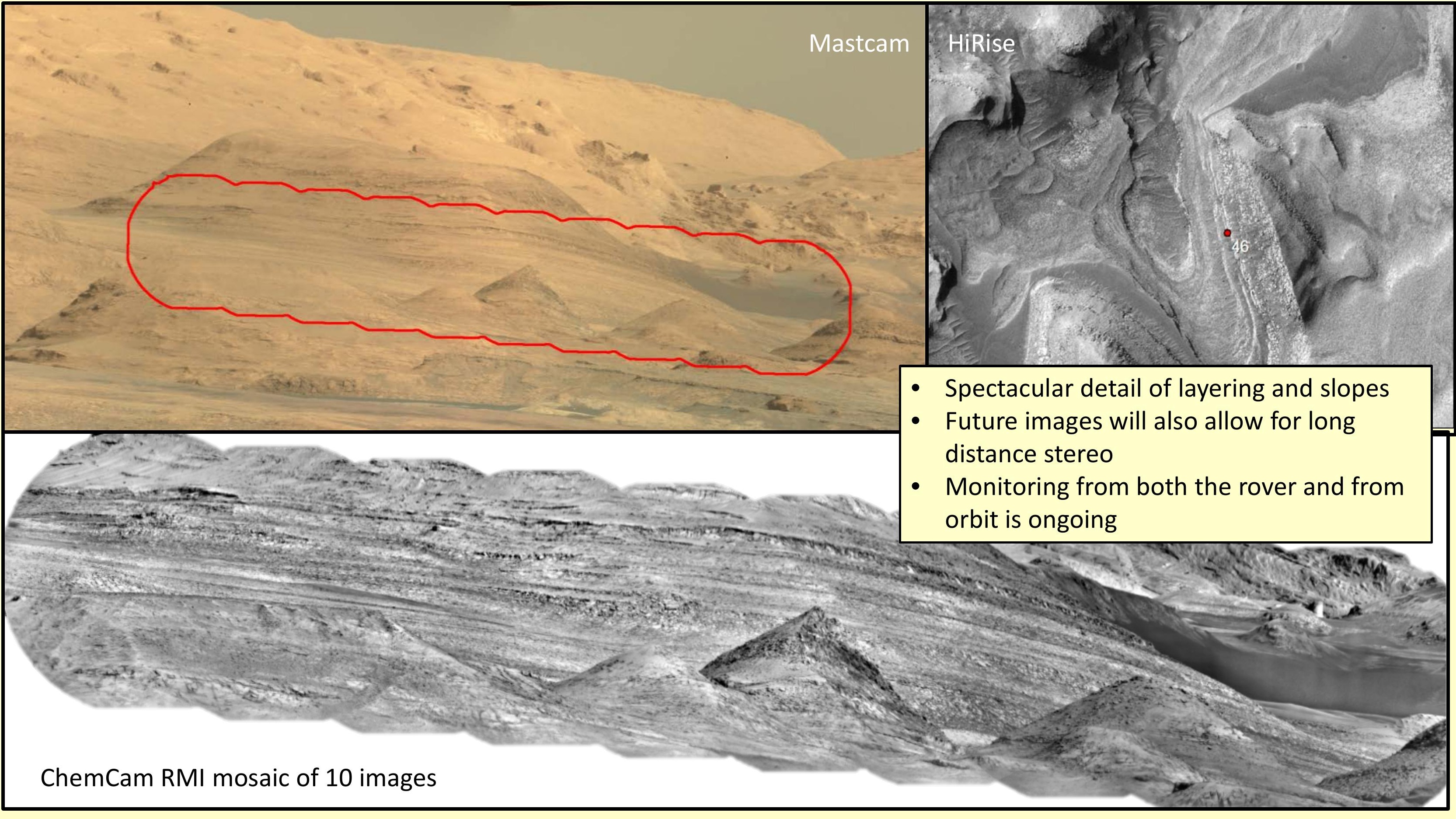




\section{Conclusions - Long distance RMI Rover Perspective imagery}

General

- Long distance high resolution rover images provide a unique perspective complementary to orbital data, and exceed orbital resolution over a large are

- Long baseline stereo is also possible with images from different locations

\section{Early results}

- Peace Vallis Fan

- Evidence for fan head channel incision into early fan deposits

- Evidence for eroded horizontally layered deposits (early fan or lacustrine sediments) embayed by more recent fan deposits

- The eroded front faces of the fan shows laterally extensive thin outcrops, that suggests sheet flow deposits

- Mt. Sharp

- RMI images reveal that a unit consisting of eroded yardangs is made up of multiple thin sub-horizontal layers, not easily detected in orbital images

- Repeat observations of slopes may provide evidence for frequency and nature of slope wasting processes

- Rover plus orbital data will allow stratigraphic analysis of exposed layered outcrops 